\title{
PÓS-MODERNIDADE, CONHECIMENTO E URGÊNCIA DE UM NOVO PARADIGMA
}

\author{
Andréia Gimenes Amaro ${ }^{1}$ \\ Viviane Kraieski de Assunção²
}

Resumo: Este estudo é resultante de uma pesquisa bibliográfica acerca da crise civilizacional característica da pós-modernidade e da inadequação da epistemologia forjada pelo sistema hegemônico dominante para lidar com problemas multidimensionais, como a degradação ambiental, a acentuação das desigualdades, a violência e o agravo da pobreza. O conhecimento científico, validado pela ciência moderna e intitulado como única via legítima de acesso ao conhecimento, relega os denominados "conhecimentos tradicionais" à marginalidade ou, em casos mais extremos, contribui para extinção destes saberes. Neste estudo evidenciamos a urgência da construção de uma nova racionalidade que promova a compreensão e o respeito às diferenças e a solidariedade entre os saberes, a relevância da hibridização do conhecimento a partir da relação dialética entre conhecimentos plurais na transição da racionalidade capitalista à racionalidade ambiental e apontamos o saber ambiental e a transdisciplinaridade como pilares da pedagogia mediadora da racionalidade ambiental.

Palavras-chave: Pós-modernidade. Conhecimento. Racionalidade.

\section{OST-MODERNITY, KNOWLEDGE AND URGENCY OF A NEW PARADIGM}

Abstract:This study is the result of a bibliographical research about the characteristic civilizational crisis of postmodernity and the inadequacy of the epistemology forged by the dominant hegemonic system to deal with multidimensional problems such as environmental degradation, accentuation of inequalities, violence and the aggravation of poverty .Scientific knowledge, validated by modern science and called the only legitimate way of access to knowledge, relegates so-called "traditional knowledge" to marginality or, in more extreme cases, contributes to the extinction of these knowledge. In this study we highlight the urgency of constructing a new rationality that promotes understanding and respect for differences and solidarity between knowledge, the relevance of the hybridization of knowledge from the dialectical relationship between plural knowledge in the transition from capitalist rationality to environmental rationality and environmental knowledge and transdisciplinarity as pillars of mediating

\footnotetext{
${ }^{1}$ Mestre em Ciências Ambientais pela Universidade do Extremo Sul Catarinense (UNESC), Criciúma, Brasil.

${ }^{2}$ Professora do Programa de Pós-Graduação em Ciências Ambientais (PPGCA) da Universidade do Extremo Sul Catarinense (UNESC), Criciúma, Brasil.
} 
pedagogy of environmental rationality.

Keywords:Postmodernity. Knowledge. Rationality.

\section{Introdução}

Iniciada no século XVI, a modernidade promoveu grandes e importantes transformações paradigmáticas que reorientaram o processo civilizatório da humanidade, inserindo-a em um "turbilhão de permanente desintegração e mudança, de luta e contradição, de ambiguidade e angústia" (BERMAN, 2007, p.24).

Ao longo de cinco séculos, a humanidade busca adequar-se ao ambiente moderno em meio às promessas de liberdade e inovação e a garantia de preservação de sua história, cultura e tradição.

\footnotetext{
O sentimento dominante, agora, é a sensação de um novo tipo de incerteza, não limitada à própria sorte e aos dons de uma pessoa, mas igualmente à respeito da futura configuração do mundo, a maneira correta de viver nele e os critérios pelos quais julgar os acertos e erros da maneira de viver (BAUMAN, 1998, p.32).
}

O modelo vigente de racionalidade constituído a partir da Revolução Científica do século XVI encontra-se em colapso e incapaz de abrandar as angústias, medos e inseguranças que caracterizam a crise vivenciada na atualidade; instalou-se uma sensação de perda irreparável, porém, sem que tenhamos a real dimensão daquilo que estamos perdendo (SANTOS, 2002, p.8). Este estudo é resultante de uma pesquisa bibliográfica acerca da crise civilizacional característica da pós-modernidade e da inadequação da epistemologia forjada pelo sistema hegemônico dominante para lidar com problemas multidimensionais e interdependentes que transcendem as propostas positivistas e a aplicação de métodos cartesianos para o encontro de possíveis soluções.

Em termos gerais, este trabalho objetivou discutir sobre a atual crise civilizacional, suas consequências e o abrandamento dos efeitos que se refletem nos variados âmbitos (social, econômico, político, ambiental, dentre outros) por 
meio de uma nova racionalidade.

Especificamente buscou-se entender o processo que intitulou 0 conhecimento científico como a única via legítima de acesso ao conhecimento, relegando às demais formas de conhecimento à marginalidade ou em casos mais extremos à extinção; discutir acerca da urgência da construção de uma nova racionalidade que promova a compreensão e o respeito às diferenças e a solidariedade entre os saberes e, por fim, abordar a relevância da hibridização do conhecimento a partir da relação dialética entre conhecimentos plurais na transição da racionalidade capitalista à racionalidade ambiental apontando o saber ambiental e a transdisciplinaridade como pilares da pedagogia mediadora da racionalidade ambiental.

\section{Pós-modernidade e a crise das certezas}

De acordo com Fritjof Capra (1982) a atual crise representa uma das mais graves e sem precedentes em toda a história da humanidade, uma crise multidimensional que coloca em risco todas as formas vida existentes no planeta.

É uma crise complexa, multidimensional, cujas facetas afetam todos os aspectos de nossa vida - a saúde e o modo de vida, a qualidade do meio ambiente e das relações sociais, da economia, tecnologia e política. É uma crise de dimensões intelectuais, morais e espirituais; uma crise de escala e premência sem precedentes em toda a história da humanidade (CAPRA, 1982, p.19).

Conforme alerta Morin (1993, p.77), trata-se de uma "policrise" em que se torna impossível destacar um único problema que subordine os demais, pois se compõe de vários problemas que interconectados, constituem o problema vital número um.

Compartilhando com esta reflexão, Boff (2014, p.18-20) ressalta que vivemos tempos de impiedade e de insensatez em que o mal estar da civilização se revela sob o fenômeno do descuido, do descaso e do abandono, perceptível, dentre outros aspectos, na degradação das relações interpessoais, no aumento da violência, da exclusão e das desigualdades sociais, no desequilíbrio ambiental

A degradação das relações pessoais, a solidão, a perda de certezas junto com a incapacidade de assumir a incerteza, tudo isso nutre um mal subjetivo cada vez mais espalhado. Como este mal das almas está escondido nas nossas cavernas interiores, como ele se desdobra de 
maneira psicossomática em insônias, dificuldades respiratórias, úlceras do estômago, doenças, não nos apercebemos da sua dimensão civilizacional coletiva e confiamo-nos ao médico, ao psicoterapeuta, ao guru (MORIN, 1993, p.69).

A produção científica pós-moderna, influenciada pelo positivismo e fundamentada em modelos cartesianos, para a qual conhecer significa quantificar, reduz as questões humanas a fórmulas e padrões sistematizados. Porém, a racionalização e o rigor científico mostram-se, muitas vezes, insuficientes para a construção de um conhecimento pertinente, capaz de auxiliar na resolução de problemas cada vez mais multidisciplinares, transversais e planetários (MORIN, 2011, p.33); isto implicaria a superação da visão fragmentada e reducionista e o redirecionamento da visão analítica para visão contextual.

Compreendida a complexidade dos problemas vivenciados na pósmodernidade, é necessário que a busca por soluções seja também pautada em tal compreensão. A realidade precisa ser percebida como uma rede de relações em que os fenômenos estão interligados e são interdependentes; o conhecimento, por sua vez, deve ser concebido e valorizado em sua diversidade, superando a hierarquização e o privilégio concedido pela vigência e interesses particulares de sistemas hegemônicos.

Os pressupostos metafísicos, os sistemas de crenças, os juízos de valor não estão antes nem depois da explicação científica da natureza ou da sociedade. São parte integrante dessa mesma explicação. A ciência moderna não é a única explicação possível da realidade e não há sequer qualquer razão científica para a considerar melhor que as explicações alternativas da metafísica, da astrologia, da religião, da arte ou da poesia. A razão porque privilegiamos hoje uma forma de conhecimento assente na previsão e no controle dos fenômenos nada tem de científico. É um juízo de valor (SANTOS, 2002, p.52).

Cabe destacar que a afirmação acima de Boaventura de Sousa Santos não tem a intenção de desqualificar a ciência moderna ou negar os progressos alcançados por seus métodos e sim destacar a relevância dos outros modos de conhecimento e de envolvimento com o mundo (NUNES, 2003, p.61).A universalidade do conhecimento científico: herança do colonialismo Por razões epistemológicas e influência de fatores econômicos e políticos, o conhecimento até então fundamentado em bases teológicas e construído por meio de métodos escolásticos, a partir da revolução científica do século XVI, passa a ser definido e 
legitimado pela ciência moderna.

A transformação epistemológica consolidada no século XIX intitula a ciência como única via legítima de acesso ao conhecimento. Nesse sentido, relega todos os demais saberes que até então orientavam as práticas de determinados grupos sociais, à marginalidade ou, em casos mais extremos, promove um epistemicídio.

No intuito de consolida esta concepção, foram forjadas pelos colonizadores estratégias racistas e etncêntricas que fundamentavam desigualdades e justificava opressões na distinção da estrutura biológica e genética dos indivíduos, relegando povos, principalmente indígenas e de origem africana, a uma situação de inferioridade, naturalizando as relações pautadas no poder e na dominação.

A codificação das diferenças entre colonizadores e colonizados com base nos traços fenotípicos, como por exemplo, a cor da pele, serviu como instrumento básico de categorização social da população que orientava os espaços a serem ocupados e os papéis sociais cabíveis a cada um. Conforme observa o sociólogo peruano Anibal Quijano (2005, p.118):

Historicamente, isso significou uma nova maneira de legitimar as já
antigas ideias e práticas de relações de superioridade/inferioridade entre
dominantes e dominados [...] demonstrou ser o mais eficaz e durável
instrumento de dominação social universal, pois dele passou a depender
outro igualmente universal, no entanto mais antigo, o intersexual ou de
gênero: os povos conquistados e dominados foram postos numa
situação natural de inferioridade, e consequentemente também seus
traços fenotípicos, bem como suas descobertas mentais e culturais.

Referindo-se às manifestações do moderno e à setorização do conhecimento no intuito de fundamentar as ações empenhadas, D'Ambrósio (1999, p.641) ressalta que "surgiram epistemologias convenientes para justificar as ciências, sistemas filosóficos para justificar o comportamento, economia para justificar as operações associadas à produção e ao mercado, e história para justificar o colonialismo".

A Europa referenciada como o grande centro difusor dos conhecimentos que compõem a história da humanidade reprime os conhecimentos construídos no seio de sociedades de nações colonizadas, colocando-os em posição de 
subalternidade (CHAKRABARTY, 2000); "essa hegemonia da Europa ajudou a espalhar uma imagem invertida, na qual o conhecimento europeu é universal e os 'outros' são conhecimentos particulares" (MARTINS, 2014, p.24).

À exceção do conhecimento científico, as demais formas de produção e transmissão de conhecimento, foram fadadas à obsolescência tornando-se artefatos de museu, apelidados de "tradicionais" (SANTOS, 2005, p.30). Em decorrência deste processo, foram desconsiderados, no conceito de "conhecimentos tradicionais", a dinâmica e os processos de ressignificação decorrentes das vivências e dos desafios impostos por circunstâncias históricas e espaço-temporais.

Frente à atual crise, os debates sobre os problemas pós-modernos e as possíveis formas de minimizá-los revelam a rivalidade entre conhecimento científico e conhecimento local/tradicional que restringem e até mesmo anulam, em algumas situações, as possibilidades de complementaridade. Santos, Meneses e Nunes (2005, p.28) chamam atenção que, pelo "fato de a ciência se constituir como um saber universal que se arroga o direito de legislar sobre as outras formas de saber e de conhecimento", é percebida frequentemente pelo mundo não ocidental como um particularismo ocidental cuja característica principal é a detenção do poder "para definir como particulares, locais, contextuais e situacionais todos os conhecimentos que com ela rivalizam".

É fato que os conhecimentos científicos e "tradicionais" possuem grandes divergências, sobretudo em suas bases constitutivas, porém, ambos convergem no sentido de consistirem em maneiras de tentar compreender e agir no mundo (CUNHA, 2009, p.302).

Lévi-Strauss afirma serem indiscutíveis as conquistas alcançadas por meio dos conhecimentos tecnocientíficos, porém ressalta que o conhecimento "tradicional", pautado nas percepções, também promoveu importantes descobertas e inovações, algumas delas talvez, ainda nem compreendidas em sua totalidade (CUNHA, 2009, p.303).

A superação da crise civilizacional discutida neste trabalho propõe o desenvolvimento de um novo saber pautado em uma visão holística e ecológica 
(CAPRA, 2006, p.25) que promova a compreensão e o respeito às diferenças, a solidariedade entre os saberes e a sinergia na construção de uma nova racionalidade.

\section{Bases para construção de uma nova racionalidade ambiental}

Os reflexos da crise pós-moderna, presentes na degradação das relações sociais, no desequilíbrio ambiental, na intensificação do abismo entre ricos e pobres alertam para o desequilíbrio do sistema dominante e a urgência de uma nova racionalidade ambiental. Porém, este processo de transição da racionalidade capitalista ou experimental para uma racionalidade ambiental "passa, pois, pelo confronto de interesses opostos e pela conciliação de objetivos comuns de diversos atores sociais" (LEFF, 2015, p.135).

Definida por Leff (2015, p.143) como "a expressão do conflito entre o uso da lei (o mercado) por uma classe, a busca do bem comum com a intervenção do Estado e a participação da sociedade civil num processo de reapropriação da natureza", a racionalidade ambiental "emerge como uma resposta social a outra racionalidade que teve seu momento histórico de construção, de legitimação e de tecnologização" (LEFF, 2015, p.142).

No entanto, viabilizar esta transição perpassa a implementação de um novo saber ambiental capaz de articular os diversos elementos e fenômenos, tratados até então de forma fragmentada, e compreender a conectividade e interdependência entre eles. Pressupõe a transição da "monocultura do saber científico para a ecologia dos saberes" (SANTOS; MENESES; NUNES, 2005, p.101).

A noção de mundo e o sistema de valores que dominaram a sociedade moderna ocidental e influenciaram de forma significativa todo o resto do planeta enfatizavam o cartesianismo como único meio válido para acessar o conhecimento e o princípio da redução como caminho para compreensão do todo.

O princípio da redução leva naturalmente a restringir o complexo ao simples. Assim, aplica às complexidades vivas e humanas a lógica mecânica e determinista da máquina artificial. Pode também cegar e conduzir a excluir 
tudo aquilo que não seja quantificável e mensurável, eliminando dessa forma, o elemento humano do humano, isto é, paixões, emoções, dores e alegrias (MORIN, 2011, p.39).

O método cartesiano tem a matemática como a chave para a compreensão do universo, nesse sentido, qualquer conhecimento que não pudesse ser comprovado com a lógica e a clareza de uma demonstração matemática, era automaticamente refutado. Cabe destacar que a aceitação dessa premissa desempenhou importante papel na instauração do atual desequilíbrio cultural (CAPRA, 1982, p.53).

Se, por um lado, o método cartesiano foi imprescindível no desenvolvimento de teorias e na concretização de importantes projetos tecnológicos, por outro, a excessiva ênfase a este método "levou à fragmentação característica do nosso pensamento em geral e das nossas disciplinas acadêmicas, [...] à crença em que todos os aspectos podem ser compreendidos se reduzidos às suas partes constituintes" (CAPRA, 1982 p.55).

O paradigma emergente preconiza a superação da parcelização do conhecimento e do reducionismo arbitrário, o reconhecimento da dimensão estética e a relação dialética entre saber científico e senso comum (SANTOS, 2002, p.37-58), considerando a pluralidade de ideias na compreensão da realidade, na elaboração de mecanismos de mudança e na inter-relação entre as dimensões natural, social e estética.

$\mathrm{Na}$ busca pela restauração da relação entre a vida e o conhecimento e da integração entre o conhecimento racional e o sensível, o saber ambiental "2 "elabora categorias para apreender o real desde o limite da existência e do entendimento, a diferença e a outredade. Dessa maneira, cria mundos de vida, constrói novas realidades e abre o curso da história para um futuro sustentável" (LEFF, 2009, p.18).

Dentre os princípios que orientam a pedagogia mediadora da construção do saber ambiental, está o que prevê a desconstrução do conhecimento meramente disciplinar e reducionista que "reduziu a complexidade para ajustá-la a uma racionalidade da modernidade" (LEFF, 2010, p.205-206). 
Compartilhando com este pensamento, Morin (2011, p.40) destaca:

\begin{abstract}
A inteligência parcelada, compartimentada, mecanicista, disjuntiva e reducionista rompe o complexo do mundo em fragmentos disjuntos, raciona os problemas, separa o que está unido, torna unidimensional o multidimensional. É uma inteligência míope que acaba por ser normalmente cega. Destrói no embrião as possibilidades de compreensão e de reflexão, reduz as possibilidades de julgamento corretivo ou da visão em longo prazo. Por isso, quanto mais os problemas se tornam multidimensionais, maior é a incapacidade de pensar sua multidimensionalidade; quanto mais a crise progride, mais progride a incapacidade de pensar a crise; mais os problemas se tornam planetários, mais eles se tornam impensáveis.
\end{abstract}

Refletindo com os autores, compreende-se que a emergência de um saber ambiental implica transcender a visão hiperespecializada sem negar a sua importância, pois consiste em "uma abertura do especialista ao todo que o envolve e a dialogicidade com outras formas de conhecimento e de visões do real, procurando a complementaridade, a motivação e a disponibilidade para atuar em equipe, e o desafio da convivência com a diversidade" (CHECHETTO, 2013, p.3233).

Nesse sentido, a transdisciplinaridade se apresenta como proposta na fundamentação das bases deste novo saber ambiental, pois, como esclarece D’Ambrósio (1999, p.648), "leva o indivíduo a tomar consciência da essencialidade do outro e da sua inserção na realidade social, planetária e cósmica" e a perceber que "essa inserção só se realiza através de um relacionamento de respeito, solidariedade e cooperação com o outro, com a sociedade, com a natureza e com o planeta".

Ressaltando a pertinência em adotar a transdisciplinaridade como forma de compreensão do mundo e como base na construção do conhecimento, D’Ambrósio (1999, p.649) alerta que "que não há espaço e tempo culturais privilegiados que permitam julgar e hierarquizar, como mais correto ou mais certo ou mais verdadeiro, complexos de explicação e convivência como a realidade que nos cerca". Complementa ainda destacando o caráter aberto e a postura respeitosa e humilde da transdisciplinaridade frente "à existência de mitos, religiões e sistemas de explicações e conhecimentos, rejeitando qualquer tipo de arrogância e prepotência". 


\section{Considerações finais}

Caracterizada pelo medo e pela incerteza, a atual crise vivenciada na atualidade revela as fragilidades e evidencia as inconsistências do paradigma dominante.

A ciência moderna,instituída para desvendar fenômenos e construir verdades por meio da lógica, do experimento e da precisão, mostra-se incapaz e ineficiente frente à complexidade de problemas sistêmicos que só podem ser compreendidos a partir da noção de interligação e interdependência.

O conhecimento científico, intitulado como único e legítimo, foi utilizado como instrumento de poder; subjugou povos, desqualificou suas culturas e saberes e, consequentemente, anulou grandes possibilidades de compreensão e atuação no mundo.

O novo paradigma discutido neste trabalho pressupõe a superação da visão fragmentada da realidade e a adoção de uma visão holística ecocêntrica que suscite a cooperação e a solidariedade e promova a emancipação e justiça social.

Porém, este processo implica a abertura a outras formas de relação e percepção do mundo; envolve a capacidade de dialogar com outros saberes, buscando, por meio do trabalho em equipe, a integração e a complementaridade, ou seja, a construção de um saber ambiental.

Neste contexto, a transdiciplinaridade possui importante papel, pois motiva a dialética entre os variados saberes e possibilita a ressignificação e hibridização dos conhecimentos a partir deste processo.

\section{Referências}

BAUMANN, Zygmunt. 0 mal-estar da pós-modernidade. Rio de Janeiro: Jorge Zahar, 1988. BERMAN, Marshall. Tudo que é sólido desmancha no ar. São Paulo: Companhia das Letras, 2007. BOFF, Leonardo. Saber cuidar. Petrópolis, RJ: Vozes, 2014. 
CAPRA, Fritjof. O ponto de mutação. São Paulo: Cultrix, 1982.

CHECHETTO, Fatima. Transdisciplinaridade e plantas medicinais no empoderamento de mulheres em busca de sustentabilidade no sul do Brasil e norte da Espanha: experiências de resgate de conhecimentos Botucatu-SP. 2013476 f. Tese (Doutorado em Agronomia) - Faculdade de Ciências Agronômicas, Universidade Estadual Paulista "Júlio de Mesquita Filho, São Paulo.

CUNHA, Manuela C. Relações e dissensões entre saberes tradicionais e saber científico. In: Cultura com Aspas e outros ensaios. São Paulo: CoascNayf, 2009. Cap: 18, p. 301-310.

D'AMBROSIO, U. Ética Ecológica. Uma proposta transdisciplinar, In: DANSERAU, Pierre; VIEIRA, Paulo Freire; Ribeiro, Maurício Andrés (orgs.). Ecologia Humana, Ética e Educação. Editora Pallotti/APED, Porto Alegre/Florianópolis, 1999, p. 639-654.

LEFF, Enrique. Discursos sustentáveis. São Paulo: Cortez, 2010.

Saber Ambiental: sustentabilidade, racionalidade, complexidade, poder. Petrópolis, RJ: Vozes, 2015.

. Complexidade, Racionalidade Ambiental e Diálogo de Saberes. Educação \&Realidade. Porto Alegre-RS, 34(3): p.17-24 set./dez. 2009. Disponívele $\mathrm{m}:<h$ ttp://seer.ufrgs.br/index.php/educacaoerealidade/article/view/95 15> Acesso em: 27 dez. 2019.

MARTINS, Paulo Henrique. DOSSIÊ O ensaio sobre o dom de Marcel Mauss: um texto pioneiro da crítica decolonial. Sociologias, Porto Alegre, ano 16, n. 36, mai./ago. 2014, p. 22-41. Disponível em <http://dx.doi.org/10.1590/15174522016003602> Acesso em: dez. mar. 2019.

MORIN, Edgar. Terra-pátria. Lisboa: Instituto Piaget, 1993. Os sete saberes necessários à educação do futuro. São Paulo: Cortez; Brasília, DF: UNESCO, 2011.

NUNES, João Arriscado. Um discurso sobre as ciências 16 anos depois. In: SANTOS, Boaventura de Sousa (org.). Conhecimento Prudente para uma Vida Decente. 'Um discurso sobre as ciências' revisitado. 2. ed. São Paulo: Cortez, 2003. p. $55-80$.

QUIJANO, Anibal. Colonialidade do poder, eurocentrismo e América Latina. Buenos Aires: CLACSO - ConsejoLatinoamericano de CienciasSociales: 2005.

SANTOS, Boaventura de Souza. La globalización del derecho: lós nuevos caminos de la regulación y la emancipación. Bogotá: ILSA, Universidad Nacional de Colombia, 1998. 
Um discurso sobre as ciências. 13. ed. São Paulo: Cortez, 2002.

(org). Semear outras soluções: os caminhos da biodiversidade e dos conhecimentos rivais. Rio de Janeiro: Civilização Brasileira, 2005.

SANTOS, Boaventura de Souza; MENESES, Maria Paula G. de. NUNES, João Arriscado. Para ampliar o cânone da ciência: a diversidade epistemológica do mundo. In: Semear outras soluções: os caminhos da biodiversidade e dos conhecimentos rivais. Rio de Janeiro: Civilização Brasileira, 2005 